\title{
Simulation of Nitrogen Emissions in a Premixed Hydrogen Flame Stabilized on a Low Swirl Burner
}

\author{
J. B. Bell, M. S. Day and M. J. Lijewski
}

Lawrence Berkeley National Laboratory, Berkeley, CA 94720, USA

\begin{abstract}
There is considerable interest in developing fuel-flexible, low emissions turbines for power generation. One approach is based on burning a variety of lean premixed fuels with relatively low flame temperatures. Such flames can be stabilized in a low swirl burner configuration, for example, using a variety of fuels such as pure hydrogen and hydrogen-seeded hydrocarbon mixtures. However, many hydrogen-rich fuels are thermodiffusively unstable and burn in cellular flame structures, which can have a significant impact on the local nitrogen chemistry. These cellular burning patterns are characterized by a local enhancement of fuel concentration and a corresponding increase in local flame temperature just downstream. In turn, these regions become sites for enhanced thermal NOx production. The structure of these cells, and their impact on the net emissions of a flame is influenced by the global flame stabilization mechanisms and by local turbulence properties. Here we investigate the role of thermodiffusive instabilities on $\mathrm{NO}_{x}$ emissions in the context of a laboratory-scale low swirl burner fueled with a lean hydrogen-air mixture at atmospheric pressure. The simulations show how the cellular burning structures characteristic of lean premixed hydrogen combustion lead to local and global enhancements in the NOx emissions. We quantify the chemical pathways that lead to the formation of $\mathrm{NO}$ and $\mathrm{N}_{2} \mathrm{O}$, and how they are enhanced within local regions of intense burning.
\end{abstract}

Keywords: turbulent premixed combustion, low Mach number flow, adaptive mesh refinement, emissions 


\section{Introduction}

Combustors based on lean premixed flames generate substantially lower $\mathrm{NO}_{x}$ emissions than equivalent nonpremixed or stoichiometric premixed systems [1]. For that reason, there has been considerable recent interest in the development of fuel-flexible premixed turbine combustors that are capable of burning lean hydrogen or hydrogen-enriched lean hydrocarbon fuels (e.g., [2-5]). For these fuels, is it expected that $\mathrm{NO}_{x}$ is produced primarily through the thermal mechanism $[1,6]$, and the reduction in emissions is believed to be a direct consequence of the lower postflame gas temperatures.

Recent laboratory experiments have shown that ultra-lean hydrocarbon flames (with fuel concentrations well below lean blow-off limits) can in fact be stabilized in a turbulent burner if the fuel mixture is enriched with $\mathrm{H}_{2}$ [3]. Hydrogen addition enhances the effective flame speed and auto-ignition processes of the mixture, [7], both of which lead to an increased resistance to strain-induced extinction. However, $\mathrm{NO}_{x}$ emissions do not decrease uniformly with increasing hydrogen enrichment relative to the hydrocarbon fuel. In a recent experimental study [2], pure $\mathrm{H}_{2}$-air flames at 8 atmospheres exhibited a pronounced "floor" at $1 \mathrm{ppm}$ NO in the exhaust stream, below which further reduction in the post-flame gas temperature had no effect on the measured emissions. Moreover, this "floor" was a factor of two or three higher than values produced in the same burner using ultra-lean hydrocarbon mixtures (seeded with hydrogen) that had comparable post-flame gas temperatures.

Lean premixed hydrogen flames are known to be thermodiffusively unstable. The thermodiffusive instability leads to cellular burning structures as noted in early work by Markstein [8] and Zeldovich [9]. Cellular burning patterns have been observed experimentally in lean $\mathrm{H}_{2} / \mathrm{O}_{2}$ mixtures by many researchers (see, for example, Bregeon et al. [10] and Mitani and Williams [11]). These relatively robust flame features are characterized by intensely-burning hotspots, where the local temperature exceeds the adiabatic flame temperature for the mean fuel mixture. The hotspots coincide with localized enhancement of the fuel-to-oxidizer ratio that is driven by differences in diffusivities (see [12] and the references cited therein). In this highly nonuniform environment, the net global production of $\mathrm{NO}_{x}$ then becomes a sum of local enhancement near super-adiabatic gas and local suppression near extinguished or weakly burning pockets. In a previous paper [13], we examined the relationship between the thermodiffusive instability and enhanced $\mathrm{NO}_{x}$ emissions. That study considered the behavior of premixed hydrogen flames over a range of equivalence ratios in two-dimensional, weakly turbulent flow. Those simulations showed an amplification of NO emissions relative to a comparable, unstrained system. The amplification was most pronounced at lower equivalence ratios; at $\phi=0.30$, the NO con- centration was more than 3 times that of the associated laminar flame. The study also showed that the increased production of emissions was correlated with the enhanced combustion intensity (fuel consumption rate) associated with the cellular flame structures that occur in the lean hydrogen mixtures. A detailed examination of the emission chemistry showed a shift in the dominant reaction pathways. At richer conditions, the predominant path for the initiation of emissions was $\mathrm{N}_{2} \rightarrow \mathrm{NNH}$. For leaner fuels, $\mathrm{N}_{2} \rightarrow \mathrm{N}_{2} \mathrm{O}$ played an increasingly important role.

In this paper, we investigate the behavior of $\mathrm{NO}_{x}$ emission in a more realistic setting. In particular, we simulate a laboratory scale model of a low swirl burner fueled by hydrogen at an equivalence ratio of $\phi=0.37$ at atmospheric pressure. The simulations are performed with a detailed kinetics mechanism that includes nitrogen emissions chemistry. The key differences between this study and the previous study are that the system is three-dimensional and the turbulence intensity is considerably higher. The goal of the study is to see how the emissions characteristics of the flame are changed at the higher turbulence conditions. In the next section, we review our computational approach and describe the study in more detail. We then provide an overview of the simulated flame and characterize the $\mathrm{NO}_{x}$-generation behavior. Finally, we examine the nitrogen chemistry in regions of differing combustion intensity.

\section{Computational Methodology}

The simulations presented here are based on a low Mach number formulation of the reacting flow equations. The methodology treats the fluid as a mixture of perfect gases. We use a mixture-averaged model for differential species diffusion and ignore Soret, Dufour, gravity and radiative transport processes. With these assumptions, the low Mach number equations for an open domain are

$$
\begin{aligned}
& \frac{\partial(\rho \boldsymbol{u})}{\partial t}+\nabla \cdot(\rho \boldsymbol{u u})=-\nabla \pi+\nabla \cdot \tau, \\
& \frac{\partial\left(\rho Y_{i}\right)}{\partial t}+\nabla \cdot\left(\rho Y_{i} \boldsymbol{u}\right)=\nabla \cdot\left(\rho \mathcal{D}_{i} \nabla Y_{i}\right)+\dot{\omega}_{i}, \\
& \frac{\partial(\rho h)}{\partial t}+\nabla \cdot(\rho h \boldsymbol{u})=\nabla \cdot\left(\frac{\lambda}{c_{p}} \nabla h\right)+ \\
& \sum_{i} \nabla \cdot\left[h_{i}\left(\rho \mathcal{D}_{i}-\frac{\lambda}{c_{p}}\right) \nabla Y_{i}\right],
\end{aligned}
$$

where $\rho$ is the density, $\boldsymbol{u}$ is the velocity, $Y_{i}$ is the mass fraction of species $i, h$ is the mass-weighted enthalpy of the gas mixture, $T$ is the temperature, and $\dot{\omega}_{i}$ is the net production rate for species $i$ due to chemical reactions. Also, $\lambda$ is the thermal conductivity, $\tau$ is the stress tensor, $c_{p}$ is the specific heat of the mixture, and $h_{i}(T)$ and $\mathcal{D}_{i}$ are the enthalpy and species mixtureaveraged diffusion coefficients of species $i$, respectively. These evolution equations are supplemented by an equation of state for a perfect gas mixture. 
The basic discretization combines a symmetric operator-split treatment of chemistry and transport with a density-weighted approximate projection method. The projection method incorporates the equation of state by imposing a constraint on the velocity divergence. The resulting integration of the advective terms proceeds on the time scale of the relatively slow advective transport. Faster diffusion and chemistry processes are treated time-implicitly. This integration scheme is embedded in a parallel adaptive mesh refinement algorithm framework based on a hierarchical system of rectangular grid patches. The complete integration algorithm is second-order accurate in space and time, and discretely conserves species mass and enthalpy. The reader is referred to [14] for details of the low Mach number model and its numerical implementation, and to [15] for previous applications of this methodology to the simulation of premixed turbulent flames. The chemical kinetics and transport are modeled using the mechanism presented in [13], which includes 15 species and 58 reversible Arrhenius reactions to describe premixed hydrogen-air combustion and subsequent $\mathrm{NO}_{x}$ formation. This mechanism was derived by rate-ofproduction and sensitivity analyses from a full reaction mechanism $[16,17]$ to obtain the minimum reaction set that describes $\mathrm{NO}$ formation in $\mathrm{H}_{2}$ oxidation at lean conditions $(\phi \approx 0.37)$ in the temperature range $1100-1600 \mathrm{~K}$. It involves NO formation through $\mathrm{NNH}$ and $\mathrm{N}_{2} \mathrm{O}$, as well as thermal NO. The nitrogen submechanism is given in Table 1.

The present study considers an idealized low-swirl configuration, where a $2.5 \mathrm{~cm}$ radius LSB nozzle issues a premixed fuel $\left(\mathrm{H}_{2}\right.$-air at $\left.\phi=0.37\right)$ into an open laboratory environment with a mean velocity of $15 \mathrm{~m} / \mathrm{s}$. The computational domain is a cubic region, $25 \mathrm{~cm}$ on a side, with an inlet face centered on the exit plane of the nozzle in order to capture the quasisteady mixing and combustion zones. All other computational boundaries are outflow at constant (atmospheric) pressure. The time-dependent Dirichlet data on the inlet face are generated from experimentally measured velocity fields taken from a comparable experimental configuration [18], but fueled at a lower rate $(6 \mathrm{~m} / \mathrm{s})$. The measured velocities are scaled uniformly by $250 \%$ in order to realize the higher flow rates of interest here. Additionally, turbulent fluctuations are superimposed on the inlet flow using the approach discussed in [19]; the turbulent intensity is scaled in each coordinate direction to match experimentally measured values of approximately $0.9 \mathrm{~m} / \mathrm{s}$, which is a factor of 5 larger than the turbulent intensity in [13]. Outside the nozzle, a $35 \mathrm{~cm} / \mathrm{s}$ upward coflow of air at $300 \mathrm{~K}$ is imposed as a model for the far-field interactions of the background air in the lab.

The simulation domain is discretized using a base mesh of $256^{3}$ uniform cells. Three levels of grid refinement, each by a successive factor of 2 , dynamically track regions of high vorticity (turbulence) and chemical reaction rates (combustion), resulting in an effective resolution of of $2048^{3}(\Delta x=122 \mu \mathrm{m})$ that extends from the nozzle to the flame surface. Note that this configuration, and the simulated flow parameters, are identical to the high-turbulence lean hydrogen case discussed in [19], except for the inclusion of detailed emission chemistry. In [19] this level of resolution was shown to adequately capture the structure of the flame, including the peak fuel consumption, the thermal field and major species profiles.

For the analysis in the next section, we construct a local coordinate system around the flame using $T$ as a progress variable. We identify the flame surface with the $T=1144 \mathrm{~K}$ isotherm and then for each node of the triangulated surface we extend the local coordinates to either side of the flame by following integral curves of $\nabla T$. Thus, for each triangular flame surface element, curves extending from each of the three nodes will bound a tube, which we will refer to as a flamelet, that has a triangular intersection with the temperature contours and extends locally normal to the progress contours. We then sample the various computed and derived quanitities along these tubes, and gather statistics for further analysis.

\section{Simulation Results and Analysis}

The basic flame structure is illustrated in Fig. 1. Fig. 1(a) illustrates the three dimensional structure and frame (b) shows a slice through the center of the domain. For the discussion and analysis here, we will focus on the central core $(r \leq 2.5 \mathrm{~cm})$ of the domain. In Fig. 2 we show images of $T$, and mole fractions of $\mathrm{OH}, \mathrm{NO}$ and $\mathrm{N}_{2} \mathrm{O}$ over the region indicated by the white box in Fig. 1. The mole fraction of $\mathrm{OH}$ provides a marker to show where the flame is burning intensely. The range of values observed here are almost 5 times the peak in a $\phi=0.37$ flat laminar flame. Regions in post-flame downstream of these intense burning regions show temperatures reaching as high as $1730 \mathrm{~K}$, well in excess of the adiabatic flame temperature of 1352. In these high temperature regions we observe enhanced concentrations of both $\mathrm{NO}$ and $\mathrm{N}_{2} \mathrm{O}$. In the case of $\mathrm{NO}$, the enhancement is fairly dramatic with peak values in excess of 10 times the laminar value. The behavior of $\mathrm{N}_{2} \mathrm{O}$ is considerably less dramatic, showing only a $25 \%$ increase over the laminar flame values.

To obtain a sense of the impact of the enhanced burning on overall emissions, we compute horizonal averages of $T$ and mole fractions of $\mathrm{NO}$ and $\mathrm{N}_{2} \mathrm{O}$ over the burner core. Fig. 3 shows those averages plotted as a function of height above the burner. The averge temperature rises through the flame brush over approximately $1.8 \mathrm{~cm}$ to a value slightly higher than the adiabatic flame temperature. $\mathrm{NO}$ and $\mathrm{N}_{2} \mathrm{O}$ rise to values of 0.9 and 0.7 parts per million respectively. The asympototic level of NO is similar to the floor observed at higher pressure in [2]. The behavior of $\mathrm{N}_{2} \mathrm{O}$ is similar to what was observed in [13]; however, at the higher turbulence levels here the average NO level has more than doubled. 
As a prelude to examining the details of the nitrogen chemistry, we first examine the consumption rate of $\mathrm{H}_{2}$, the production rates of $\mathrm{NO}$ and $\mathrm{N}_{2} \mathrm{O}$ and the heat release. Images of these quantities are presented in Fig. 4. As expected at these conditions, all four of these quantities are highly correlated. Peaks of $\mathrm{NO}$ and $\mathrm{N}_{2} \mathrm{O}$ production are higher than the corresponding laminar flame values by factors of 30 and 15 , respectively. The results here are qualitatively consistent with the results in [13]; but with much higher intensities. Fuel consumption rates and NO and $\mathrm{N}_{2} \mathrm{O}$ production rates are a factor of 5 higher than in [13]. Also, at the higher turbulent intensity shown here the flame does not show complete extinction in the gaps between intensively burning cells, rather it only shows a sharp reduction in consumption. This effect is illustrated in Fig. 5, which compares the flame surface from a freely propagating hydrogen flame at $\phi=0.37$ to the flame surface in the core of the low swirl burner. These image are colored by local consumption based flame speed, which is defined by integrating the fuel consumption over each flamelet and normalizing by the fuel density in the inflow stream. These images show that the turbulence leads to finer-scale features with more intense burning than are observed in the thermodiffisively unstable freeely-propagating flame. In Fig. 6 we present a joint PDF of mean curvature versus local fuel-consumption based flame speed that shows that much of the burning occurs at 2.4-3.8 times the laminar flame speed but can reach values as high as 5 times the laminar speed. Furthermore, the intense burning regions in the turbulent flame have a characteristic ridge-like structure as compared to the bulb-like structures associated with cellular burning, which is illustrated quantitatively in the PDF of Gaussian curvature along the flame front shown in Fig. 7.

Next, we focus on the details of the nitrogen chemistry. To quantify the details of the emissions chemistry and how it depends on burning intensity, we group the flamelets into 10 bins based on the peak fuel consumption on the flamelet. Figure 8(a) shows an image of part of the flame surface colored by the bin number associated with that triangle. For several representative fuel consumption bins, Figures 8(b-d) show conditional mean NO production rates (only the most significantly contributing reactions are shown, labeled according to the numbering in Table 1). The conditional mean total NO production rate (shown as the solid black line in each figure) consists primarily of contributions from the "thermal" $\left(\omega_{\mathrm{NO}}\right.$-therm, dotted black line $)$ and $\mathrm{NNH}\left(\omega_{\mathrm{NO}}-\mathrm{NNH}\right.$ dashed black line) routes. The reaction profiles show dramatic increases in NO production in the intermediate and strong burning regimes.

The thermal route consists of three reactions that create $\mathrm{NO}$ from $\mathrm{O}_{2}$ (R49), $\mathrm{N}_{2}$ (R50b) and $\mathrm{N}$ (R48), and is typically associated with high temperatures $(T \gtrsim 1700)$. (Here $\mathrm{R} 50 \mathrm{~b}$ refers the reaction 50 in the reverse direction.) The $\mathrm{NNH}$ route is initiated when $\mathrm{N}_{2}$ combines with $\mathrm{H}$ to form $\mathrm{NNH}$ (R57). $\mathrm{NNH}$ then reacts to produce either $\mathrm{N}_{2} \mathrm{O}$ (R53) or the pair, $\mathrm{NO}$ and NH (R55). Some of the NH reacts to N (R40, $\mathrm{R} 41$ ), and then proceeds to NO through the thermal route (R48, R49) or is converted directly to NO, primarily through R44. Even though most of the nitrogen passing through the NNH route is recycled back to $\mathrm{N}_{2}$, the fraction that reacts to $\mathrm{NO}$ still accounts the bulk of the NO production.

Of the $\mathrm{N}_{2} \mathrm{O}$ created by $\mathrm{R} 53$ or R35b, approximately $90 \%$ is converted back to $\mathrm{N}_{2}$ (R37), and the remainder reacts to NO. We note that in the cold regions of the flame R31 and R32 compete to balance $\mathrm{NO}$ and $\mathrm{N}_{2} \mathrm{O}$. At low temperatures $(<\approx 700 \mathrm{~K}$, these reactions combine to yield a weak destruction of NO. (This effect is too weak to be seen in Fig. 4.) At higher temperatures R44b and R30 also begin to compete in the balance of $\mathrm{NO}$ and $\mathrm{N}_{2} \mathrm{O}$. It is interesting that both the NNH and thermal routes become significant when $T \gtrsim 1300$; the adiabatic flame temperature for this fuel mixture is $1352 \mathrm{~K}$, and peak temperatures are observed in excess of $1600 \mathrm{~K}$ across much of the post-flame region (see Fig. 2. Similar increases in NO production by the $\mathrm{NNH}$ and thermal routes were observed in methane-air mixtures seeded with $\mathrm{H}_{2}$ [7].

Fig. 8 shows that although the NO production rates in the intensely burning regions are amplified by as much as a factor of 13 , most of the flame is actually consuming fuel at weak to intermediate rates; the extreme peaks in NO production are quite localized. Figure 9(a) shows the volume-integrated NO production rate as a function of $T$. The majority of NO is generated near $1500 \mathrm{~K}$. Also, we see that $\approx 80 \%$ of the NO is created through the NNH route, while $\approx 20 \%$ is generated via the thermal route. Figure 9(b) shows a quantitative reaction path diagram, where the thickness of the graph edges is scaled to the transfer rate of nitrogen atoms between species pairs. The data is integrated over the flame region where $r<2.5 \mathrm{~cm}$, and over the entire temperature range. Contributions to each edge are collected into 3 groups of peak fuel consumption (see caption), and are represented as percentages of total NO production. The $\mathrm{N}_{2} \rightarrow \mathrm{N}_{2} \mathrm{O}$ path shows a negative contribution for the weak flames, indicating that the path actually reverses. In spite of the extremely large NO production rates in the hotspot regions, the weak to intermediate burning regions of the flame account for about $90 \%$ of the total NO production.

\section{Discussion and Conclusions}

We have presented simulations of a lean premixed hydrogen flame stabilized on a low-swirl burner with detailed kinetics including nitrogen emission chemistry. The simulations show a significant increase in production of NO compared to both the flat laminar flame and simulations at lower turbulent intensities. The present findings are consistent with experimental observations at higher pressure in [2]. A detailed examination of the emissions chemistry shows that the dominant pathway is through an $\mathrm{NNH}$ pathway 
with the thermal mechanism playing a much smaller role, accounting for only about $20 \%$ of the overall $\mathrm{NO}$ emissions. In future work, we plan to investigate emissions chemistry at higher pressures more characteristic of a realistic turbine environment.

\section{Acknowledgments}

This work was supported by the DOE Applied Mathematics Research Program of the DOE Office of Advanced Scientific Computing Reserach under the U.S. Department of Energy Contract No. DE-AC0205CH11231. The authors thank Peter Glarborg for providing us with the emissions chemistry used in this work.

\section{References}

[1] S. Correa, Combust. Sci. Technol. 87 (1992) 329-362.

[2] R. K. Cheng, D. Littlejohn, P. A. Strakey, T. Sidwell, Proc. Combust. Inst. 32 (2009) 3001-3009.

[3] D. Littlejohn, R. K. Cheng, Proc. Combust. Inst. 31 (2007) 3155-3162.

[4] M. Nakahara, T. Shirasuna, J. Hashimoto, J. Therm. Sci. Technol. 4 (2009) 190-201.

[5] U. S. Dept. of Energy, Office of Fossil Energy, Hydrogen from Coal Program: Research, Development and Demonstration Plan, available at http://fossil.energy.gov/programs/ fuels/publications/programplans/ 2009_Draft_H2fromCoal_Sept30_web.pdf (Sept. 2009).

[6] J. A. Miller, C. T. Bowman, Prog. Energy Combust. Sci. 15 (4) (1989) 287-338.

[7] E. Hawkes, J. H. Chen, Combust. Flame 138 (2004) 242-258.

[8] G. H. Markstein, The Journal of Chemical Physics 17 (4) (1949) 428-429.

[9] Y. B. Zeldovich, Theory of Combustion and Detonation in Gases (in Russian), Acad. Sci. USSR, 1944.

[10] B. Bregeon, A. S. Gordon, F. A. Williams, Combustion and Flame 33 (1978) 33-45.

[11] T. Mitani, F. A. Williams, Combust. Flame 39 (1980) 169-190.

[12] M. S. Day, J. B. Bell, P.-T. Bremer, V. Pascucci, V. Beckner, M. Lijewski, Combust. Flame 156 (2009) 1035-1045.

[13] M. S. Day, J. B. Bell, X. Gao, P. Glarborg, Proceedings of the Combustion Institute 33 (1) (2011) 1591 - 1599.

[14] M. S. Day, J. B. Bell, Combust. Theory Modelling 4 (2000) 535-556.

[15] J. B. Bell, M. S. Day, J. F. Grcar, Proc. Combust. Inst. 29 (2002) 1987-1993.

[16] T. Mendiara, P. Glarborg, Combust. Flame 156 (2009) 1937-1949.

[17] T. Mendiara, P. Glarborg, Energ. Fuels 23 (2009) $3565-3572$.

[18] P. Petersson, J. Olofsson, C. Brackman, H. Seyfried, J. Zetterberg, M. Richter, M. Alden, M. Linne, R. Cheng, A. Nauert, D. Geyer, A. Dreizler, Appl. Opt 46 (2007) 3928-3936.

[19] M. S. Day, J. B. Bell, R. K. Cheng, S. Tachibana, V. E. Beckner, M. J. Lijewski, Cellular burning in lean premixed turbulent hydrogen-air flames: coupling experimental and computational analysis at the laboratory scale, Vol. 180 of Journal of Physics Conference Series: SciDAC 2009 (W. Tang, Ed.), Institute of Physics Publishing, San Diego, CA, 2009. 
Table 1: Thermal and $\mathrm{NNH} / \mathrm{N}_{2} \mathrm{O}$ formation routes for NO. For each reaction, $i$, the forward progress rate $k_{i}=A_{i} T^{n_{i}} \exp \left(-E_{i} / R T\right)\left(\right.$ moles $\left./ \mathrm{cm}^{3} \cdot s\right)$, where $A_{i}, n_{i}, E_{i}(\mathrm{cal} / \mathrm{g} \cdot \mathrm{K})$ are given below.

\begin{tabular}{|c|c|c|c|c|}
\hline No. & Reaction & $A$ & $n$ & $E$ \\
\hline 30 & $\mathrm{NO}+\mathrm{O}(+\mathrm{M}) \rightleftharpoons \mathrm{NO}_{2}(+\mathrm{M})$ & $1.3 \mathrm{E} 15$ & -0.75 & 0 \\
\hline 31 & $\mathrm{NO}+\mathrm{HO}_{2} \rightleftharpoons \mathrm{NO}_{2}+\mathrm{OH}$ & $2.1 \mathrm{E} 12$ & 0.00 & -497 \\
\hline 32 & $\mathrm{NO}_{2}+\mathrm{H} \rightleftharpoons \mathrm{NO}+\mathrm{OH}$ & $1.3 \mathrm{E} 14$ & 0.00 & 362 \\
\hline 33 & $\mathrm{NO}_{2}+\mathrm{O} \rightleftharpoons \mathrm{NO}+\mathrm{O}_{2}$ & $1.1 \mathrm{E} 14$ & -0.52 & 0 \\
\hline 34 & $2 \mathrm{NO}_{2} \rightleftharpoons 2 \mathrm{NO}+\mathrm{O}_{2}$ & $4.5 \mathrm{E} 12$ & 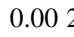 & 27599 \\
\hline 35 & $\mathrm{~N}_{2} \mathrm{O}(+\mathrm{M}) \rightleftharpoons \mathrm{N}_{2}+\mathrm{O}(+\mathrm{M})$ & $1.3 \mathrm{E} 12$ & 0.006 & 62570 \\
\hline 36 & $\mathrm{~N}_{2} \mathrm{O}+\mathrm{H} \rightleftharpoons \mathrm{N}_{2}+\mathrm{OH}$ & $3.3 \mathrm{E} 10$ & 0.00 & 4729 \\
\hline 37 & $\mathrm{~N}_{2} \mathrm{O}+\mathrm{H} \rightleftharpoons \mathrm{N}_{2}+\mathrm{OH}$ & $4.4 \mathrm{E} 14$ & 0.001 & 19254 \\
\hline 38 & $\mathrm{~N}_{2} \mathrm{O}+\mathrm{O} \rightleftharpoons \mathrm{NO}+\mathrm{NO}$ & $9.2 \mathrm{E} 13$ & $0.002-2$ & 27679 \\
\hline 39 & $\mathrm{~N}_{2} \mathrm{O}+\mathrm{O} \rightleftharpoons \mathrm{N}_{2}+\mathrm{O}_{2}$ & $3.7 \mathrm{E} 12$ & 0.001 & 15936 \\
\hline 40 & $\mathrm{NH}+\mathrm{H} \rightleftharpoons \mathrm{N}+\mathrm{H}_{2}$ & $3.0 \mathrm{E} 13$ & 0.00 & 0 \\
\hline 41 & $\mathrm{NH}+\mathrm{O} \rightleftharpoons \mathrm{NO}+\mathrm{H}$ & $9.2 \mathrm{E} 13$ & 0.00 & 0 \\
\hline 42 & $\mathrm{NH}+\mathrm{OH} \rightleftharpoons \mathrm{N}+\mathrm{H}_{2} \mathrm{O}$ & $5.0 \mathrm{E} 11$ & 0.50 & 2000 \\
\hline 43 & $\mathrm{NH}+\mathrm{O}_{2} \rightleftharpoons \mathrm{NO}+\mathrm{OH}$ & $1.3 \mathrm{E} 06$ & 1.50 & 100 \\
\hline 44 & $\mathrm{NH}+\mathrm{NO} \rightleftharpoons \mathrm{N}_{2} \mathrm{O}+\mathrm{H}$ & $2.9 \mathrm{E} 14$ & -0.40 & 0 \\
\hline 45 & $\mathrm{NH}+\mathrm{NO} \rightleftharpoons \mathrm{N}_{2} \mathrm{O}+\mathrm{H}$ & $-2.2 \mathrm{E} 13-$ & -0.23 & 0 \\
\hline 46 & $\mathrm{NH}+\mathrm{NO} \rightleftharpoons \mathrm{N}_{2}+\mathrm{OH}$ & $2.2 \mathrm{E} 13$ & -0.23 & 0 \\
\hline 47 & $\mathrm{NH}+\mathrm{NO}_{2} \rightleftharpoons \mathrm{N}_{2} \mathrm{O}+\mathrm{OH}$ & $1.0 \mathrm{E} 13$ & 0.00 & 0 \\
\hline 48 & $\mathrm{~N}+\mathrm{OH} \rightleftharpoons \mathrm{NO}+\mathrm{H}$ & $3.8 \mathrm{E} 13$ & 0.00 & 0 \\
\hline 49 & $\mathrm{~N}+\mathrm{O}_{2} \rightleftharpoons \mathrm{NO}+\mathrm{O}$ & $6.4 \mathrm{E} 09$ & 1.00 & 6280 \\
\hline 50 & $\mathrm{~N}+\mathrm{NO} \rightleftharpoons \mathrm{N}_{2}+\mathrm{O}$ & $2.1 \mathrm{E} 13$ & 0.00 & 0 \\
\hline 51 & $\mathrm{NNH} \rightleftharpoons \mathrm{N}_{2}+\mathrm{H}$ & $6.5 \mathrm{E} 07$ & 0.00 & 0 \\
\hline 52 & $\mathrm{NNH}+\mathrm{H} \rightleftharpoons \mathrm{N}_{2}+\mathrm{H}_{2}$ & $1.0 \mathrm{E} 14$ & 0.00 & 0 \\
\hline 53 & $\mathrm{NNH}+\mathrm{O} \rightleftharpoons \mathrm{N}_{2} \mathrm{O}+\mathrm{H}$ & $1.0 \mathrm{E} 14$ & 0.00 & 0 \\
\hline 54 & $\mathrm{NNH}+\mathrm{O} \rightleftharpoons \mathrm{N}_{2}+\mathrm{OH}$ & $8.0 \mathrm{E} 13$ & 0.00 & 0 \\
\hline 55 & $\mathrm{NNH}+\mathrm{O} \rightleftharpoons \mathrm{NH}+\mathrm{NO}$ & $5.0 \mathrm{E} 13$ & 0.00 & 0 \\
\hline 56 & $\mathrm{NNH}+\mathrm{OH} \rightleftharpoons \mathrm{N}_{2}+\mathrm{H}_{2} \mathrm{O}$ & $5.0 \mathrm{E} 13$ & 0.00 & 0 \\
\hline 57 & $\mathrm{NNH}+\mathrm{O}_{2} \rightleftharpoons \mathrm{N}_{2}+\mathrm{HO}_{2}$ & $2.0 \mathrm{E} 14$ & 0.00 & 0 \\
\hline 58 & $\mathrm{NNH}+\mathrm{O}_{2} \rightleftharpoons \mathrm{N}_{2}+\mathrm{H}+\mathrm{O}_{2}$ & $5.0 \mathrm{E} 13$ & 0.00 & 0 \\
\hline
\end{tabular}




\section{List of Figure Captions}

Figure 1. (148 mm = 335 words) (a) Cutaway of flame snapshot. Isovolume (enclosed in blue, colored on exposed surfaces) of NO concentration, fuel boundary is semi-opaque red surface, and grey represents vortical structures at shear layer of turbulent swirling flow. (b) Slice showing $X\left(H_{2}\right)$ through centerline of the burner. The color bar indicates the values, where $(\operatorname{Min}, \operatorname{Max})=(0,0.1345)$. The same color scheme is used for Figs. 2 and 4; value ranges are specified in each respective caption.

Figure 2. ( $82 \mathrm{~mm}=180$ words) Profiles in the burner core corresponding to the white rectangle in Fig. 1 (Values ranges specied in brackets for each): (a) $\mathrm{X}(\mathrm{OH})[0, .0056]$; (b) Temperature $[300,1625] \mathrm{K}$; (c) $\mathrm{X}(\mathrm{NO})[0,1.9 \mathrm{E}-6]$; and (d) $\mathrm{X}\left(\mathrm{N}_{2} \mathrm{O}\right)[0,8.9 \mathrm{E}-7]$.

Figure 3. ( $69 \mathrm{~mm}=152$ words) Horizontal averages of $T$ and average $X(N O)$ and $X\left(N_{2} \mathrm{O}\right)$ over the burner core $(r \leq 0.025)$

Figure 4. ( $88 \mathrm{~mm}=194$ words) Profiles in the burner core corresponding to the white rectangle in Fig. 1 (Values ranges specied in brackets for each): (a) Consumption rate of fuel $\left(\mathrm{H}_{2}\right)[0,28.7] \mathrm{kg} / \mathrm{m}^{3} \mathrm{~s}$; (b) Heat release [0,2.E9] $\mathrm{J} / \mathrm{m}^{3} \mathrm{~s}$; (c) Production rate of NO $[-2.25 \mathrm{e}-4,2.91 \mathrm{e}-3] \mathrm{kg} / \mathrm{m}^{3} \mathrm{~s}$; and (d) Production rate of $\mathrm{N}_{2} \mathrm{O}[-1.3 \mathrm{e}-5,2.26 \mathrm{e}-3] \mathrm{kg} / \mathrm{m}^{3} \mathrm{~s}$. Figure 5 .

( $63 \mathrm{~mm}=277$ words) Comparison of flame surface from freely propagating flame and flame in the core of the low swirl burner. Images are colored by the local fuel consumption speed.

Figure 6. ( $70 \mathrm{~mm}=154$ words $)$ Joint PDF of mean curvature versus local consumption-based flame speed on flame surface conditioned by fuel consumption above 0.5 times laminar value.

Figure 7. ( $46 \mathrm{~mm}=101$ words) PDF of Gaussian curvature of low swirl burner (LSB) compared to the freely propagating flame (FPF) illustrating the shift from bulbous structures to ridge-like structures.

Figure 8. (132 mm = 581 words $)$ Emission chemistry in a turbulent lean hydrogen-air low-swirl flame. The flame surface is divided into local flamelets, and binned by peak burning rate. (a) $\mathrm{T}=1144 \mathrm{~K}$, colored where it intersects the flamelets by corresponding bin number (blue $=1$, red $=10$ ). (b-d) Conditional mean rates for the dominant reactions producing NO, along with the total NO production (black curve). Dotted black curves represent the total contribution due to the "thermal" sub-mechanism; dashed curves indicate the total due to the NNH sub-mechanism.

Figure 9. (133 $\mathrm{mm}=293$ words) (a)Distribution of integrated emissions production, and (b) Path diagram quantifying the integrated transfer rate of $\mathrm{N}$ atoms between species, normalized by the total rate of $\mathrm{N}$ atoms into NO. Each path indicates the contribution (in percent of NO production rate) from the weak $\left(\omega_{P e a k}=0-4 \omega_{P e a k, 0.37}\right.$, blue $)$, intermediate $\left(\omega_{\text {Peak }}=4-9 \omega_{\text {Peak }, 0.37}\right.$, green $)$ and strong $\left(\omega_{\text {Peak }}=9-13 \omega_{\text {Peak }, 0.37}\right.$, red $)$ flames, where $\omega_{P e a k, 0.37}$ is the peak consumption rate of the flat flame at $\phi=0.37$. 

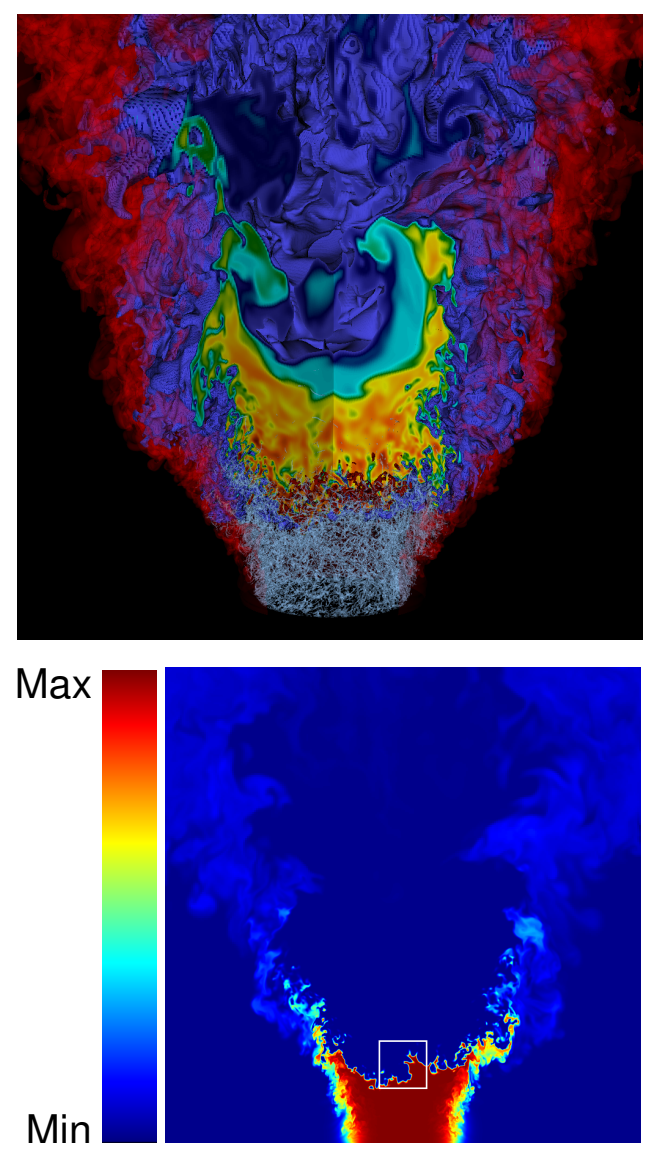

Fig. 1: (a) Cutaway of flame snapshot. Isovolume (enclosed in blue, colored on exposed surfaces) of NO concentration, fuel boundary is semi-opaque red surface, and grey represents vortical structures at shear layer of turbulent swirling flow. (b) Slice showing $X\left(H_{2}\right)$ through centerline of the burner. The color bar indicates the values, where (Min,Max $)=(0,0.1345)$. The same color scheme is used for Figs. 2 and 4; value ranges are specified in each respective caption. 

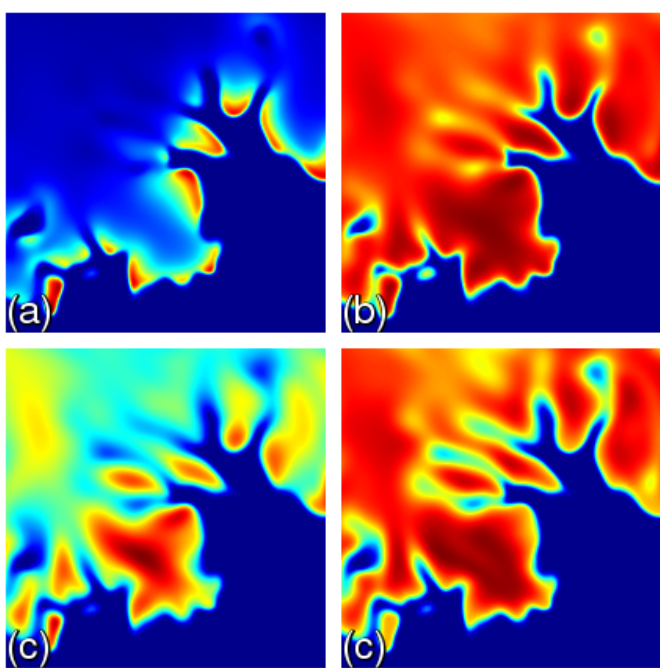

Fig. 2: Profiles in the burner core corresponding to the white rectangle in Fig. 1 (Values ranges specied in brackets for each): (a) $\mathrm{X}(\mathrm{OH})[0, .0056]$; (b) Temperature $[300,1625] \mathrm{K}$; (c) $\mathrm{X}(\mathrm{NO})[0,1.9 \mathrm{E}-6]$; and (d) $\mathrm{X}\left(\mathrm{N}_{2} \mathrm{O}\right)[0,8.9 \mathrm{E}-7]$. 


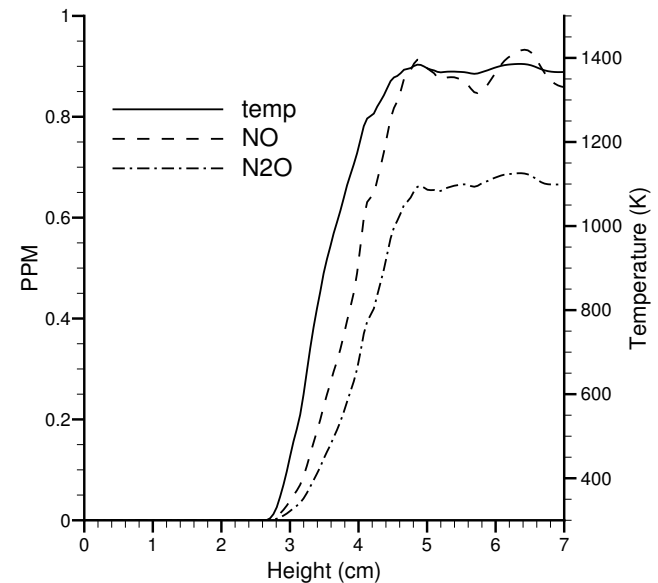

Fig. 3: Horizontal averages of $T$ and average $X(N O)$ and $X\left(N_{2} \mathrm{O}\right)$ over the burner core $(r \leq 0.025)$. 

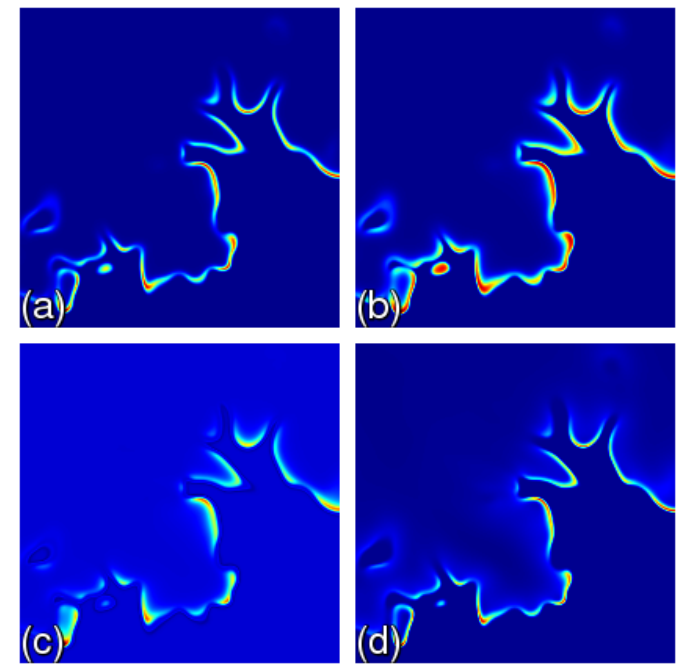

Fig. 4: Profiles in the burner core corresponding to the white rectangle in Fig. 1 (Values ranges specied in brackets for each): (a) Consumption rate of fuel $\left(\mathrm{H}_{2}\right)[0,28.7] \mathrm{kg} / \mathrm{m}^{3} \mathrm{~s}$; (b) Heat release $[0,2 . \mathrm{E} 9] \mathrm{J} / \mathrm{m}^{3} \mathrm{~s}$; (c) Production rate of NO $[-2.25 \mathrm{e}-4,2.91 \mathrm{e}-3] \mathrm{kg} / \mathrm{m}^{3} \mathrm{~s}$; and (d) Production rate of $\mathrm{N}_{2} \mathrm{O}$ $[-1.3 \mathrm{e}-5,2.26 \mathrm{e}-3] \mathrm{kg} / \mathrm{m}^{3} \mathrm{~s}$. 


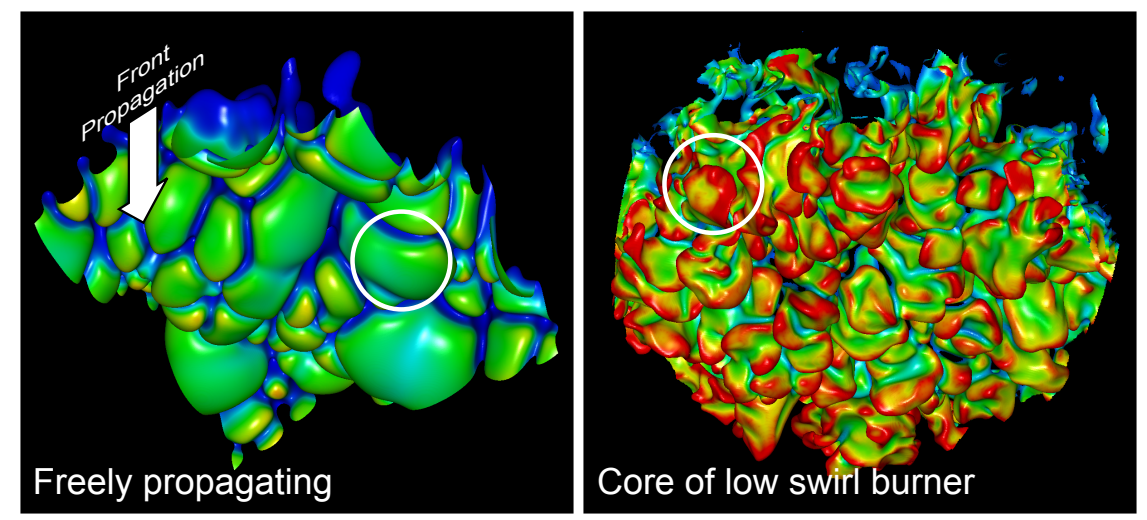

Fig. 5: Comparison of flame surface from freely propagating flame and flame in the core of the low swirl burner. Images are colored by the local fuel consumption speed. 


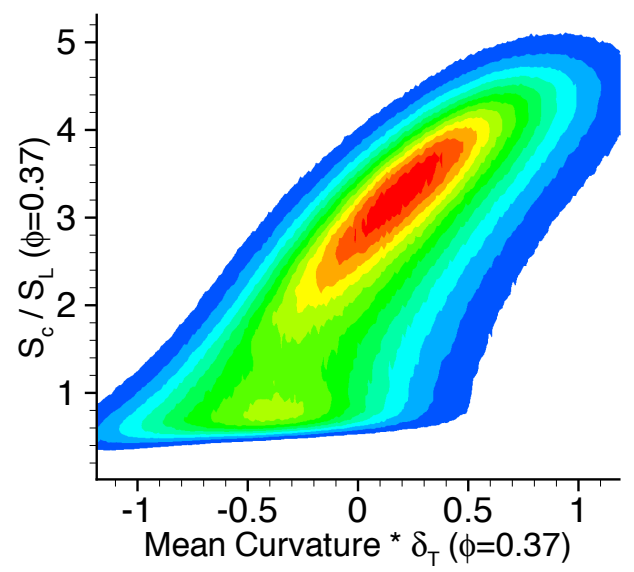

Fig. 6: Joint PDF of mean curvature versus local consumption-based flame speed on flame surface conditioned by fuel consumption above 0.5 times laminar value. 


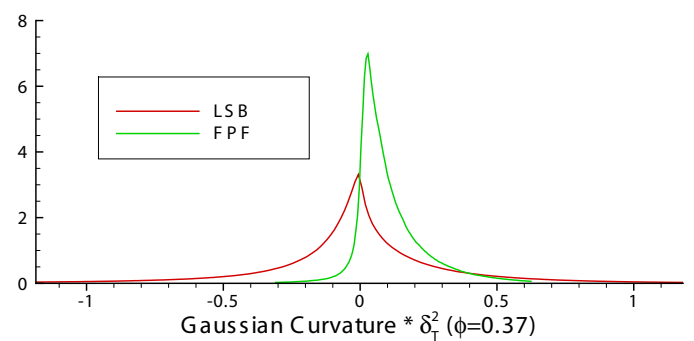

Fig. 7: PDF of Gaussian curvature of low swirl burner (LSB) compared to the freely propagating flame (FPF) illustrating the shift from bulbous structures to ridge-like structures. 


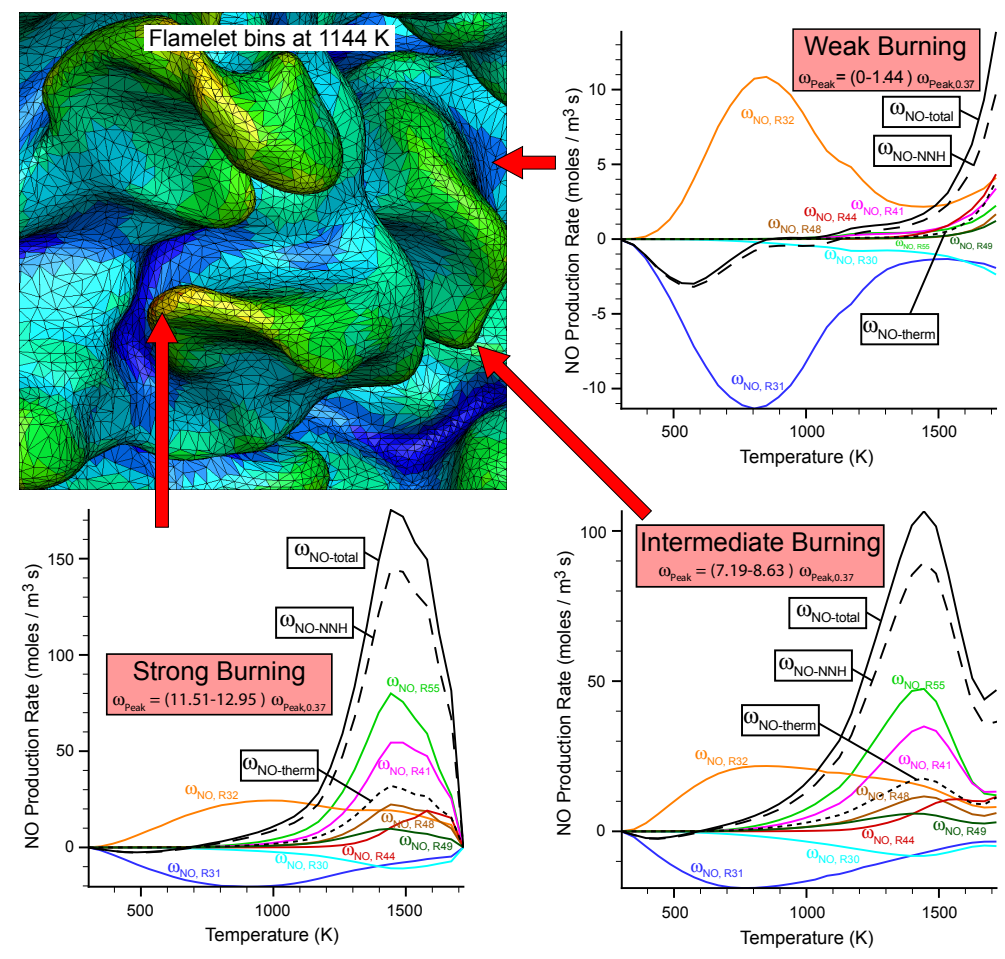

Fig. 8: Emission chemistry in a turbulent lean hydrogenair low-swirl flame. The flame surface is divided into local flamelets, and binned by peak burning rate. (a) $\mathrm{T}=1144 \mathrm{~K}$, colored where it intersects the flamelets by corresponding bin number (blue $=1$, red=10). (b-d) Conditional mean rates for the dominant reactions producing $\mathrm{NO}$, along with the total NO production (black curve). Dotted black curves represent the total contribution due to the "thermal" submechanism; dashed curves indicate the total due to the $\mathrm{NNH}$ sub-mechanism. 

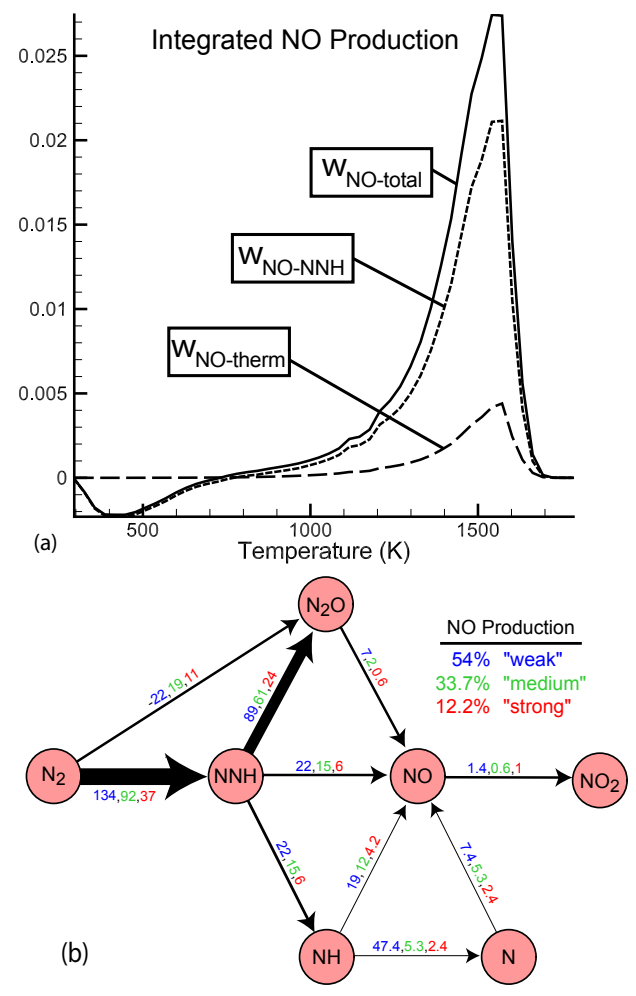

Fig. 9: (a)Distribution of integrated emissions production, and (b) Path diagram quantifying the integrated transfer rate of $\mathrm{N}$ atoms between species, normalized by the total rate of $\mathrm{N}$ atoms into NO. Each path indicates the contribution (in percent of NO production rate) from the weak $\left(\omega_{P e a k}=0-4 \omega_{P e a k, 0.37}\right.$, blue $)$, intermediate $\left(\omega_{\text {Peak }}=4-9 \omega_{P e a k, 0.37}\right.$, green $)$ and strong $\left(\omega_{\text {Peak }}=\right.$ $9-13 \omega_{P e a k, 0.37}$, red) flames, where $\omega_{P e a k, 0.37}$ is the peak consumption rate of the flat flame at $\phi=0.37$. 